\title{
The Integration of Newly Graduated Construction Managers into the South African Construction Industry
}

\author{
Thulani Khoza ${ }^{1}$, Mark Abrey² and John Smallwood ${ }^{3}$
}

1 Nelson Mandela University, Port Elizabeth, South Africa, khozathulani@gmail.com

2 Nelson Mandela University, Port Elizabeth, South Africa, mhsabrey@yahoo.com

3 Nelson Mandela University, Port Elizabeth, South Africa, john.smallwood@mandela.ac.za

\begin{abstract}
Anecdotal evidence indicates that newly graduated Construction Managers experience difficulty in terms of integrating into the construction industry.

Construction Managers (CMs) and Construction Project Managers (CPMs) registered with the South African Council for the Project and Construction Management Professions (SACPCMP) were surveyed by means of an online survey to determine the status quo with respect to newly graduated construction managers.

In terms of findings, graduates were rated: average to good / good in terms of overall performance, however, marginally so; marginally below average in terms of their performance relative to the functions of management work; highest relative to computer literacy, numeracy, and trust and honesty in terms of attributes / skills during probation; highest relative to computer literacy, numeracy, and written communication after probation; highest relative to construction technology, construction science, and research methodology in terms of knowledge areas, and highest relative to personal integrity in terms of ten core competencies.
\end{abstract}

Conclusions include: graduates are employable; challenges exist in terms of newly graduated Construction Managers, and tertiary built environment education must enhance graduates' attributes, knowledge, skills, core competencies, and emotional intelligence (EI).

Recommendations include: tertiary institutions should ensure that graduates are well versed and developed during their four-year study period; emphasis should be placed on developing core competencies and El; employers should subject graduates to graduate training programmes; the interface between industry and tertiary education should be optimised through forums, and students should undertake construction-related vacation work and generic part-time work.

(c) 2020 The Authors. Published by Budapest University of Technology and Economics \& Diamond Congress Ltd Peer-review under responsibility of the Scientific Committee of the Creative Construction Conference 2020.

Keywords: construction management, graduates, integration, performance

\section{Introduction}

In any country, education and skills levels are contributory to economic growth because highly skilled individuals such as entrepreneurs create jobs and adequately skilled people can be absorbed into employment when jobs are generated [1].

The concern emerges from the stature of young people completing high school, and continues with a vulnerable tertiary education and training system, which manifests itself in the low figures of knowledgeable people emerging from either the formal education system, or from skills development 
programmes, and finally in the non-alignment of the skills of those qualifying and the skills needs of employers [1].

The nature of the construction industry in South Africa, combined with the uncertainty of worldwide competitiveness and evolving regulatory necessities, has developed the need for well taught and trained construction management graduates who can excel [2]. Similarly, firms are consistently challenged to appoint people who will increase the value of their businesses and contribute to organisational success [3]. This challenge is amplified in South Africa where there is an increasing shortage of skilled people [3]. An implication of this reality is that it is no longer sufficient for graduates to merely possess a degree or good grades, as it is imperative that they possess a range of aptitudes that promote employability, and integrate into new methods of production [4].

According to Jonck [5], research indicates that there was no measurable relationship between skills advancement in higher education institutions and the expanded likelihood of employment. This observation serves as one of the reasons why graduate employability has surfaced as a profoundly topical and challenging topic because employers are of the sentiment that construction management graduates are not appropriately groomed for the world of work. Therefore, it has become imperative that built environment-related academia deliver qualitative education that develops the requisite skills necessary for graduates to respond to the needs of their employers [2].

Given the aforementioned, a study was conducted to determine the status quo with respect to newly graduated construction managers in terms of their:

- attributes, skills, core competencies, and emotional intelligence at various stages, and

- performance relative to knowledge areas and the functions of management work.

\section{Review of the literature}

\subsection{Attributes and skills}

Love, Haynes \& Irani [2] state that intelligence, flexibility, adaptiveness, and the ability to deal with uncertainty and rapid change are the essential personal attributes sought by potential employers.

Ogunsanmi [6] categorises the essential skill requirements for Construction Managers as: personal; managerial; industry and business; professional; technical; legal and contractual, and people. Furthermore, Ogunsanmi [6] states that it is imperative that construction managers possess the required skills that will enable them to function efficiently and profitably in high pressure situations. However, Love et al. [2] contend that construction management graduates are often unjustifiably criticised by their employers due to the fact that they are new to the workforce and subsequently have constrained, if any, viable experience. Therefore, it is imperative that construction management programmes produce graduates who have the fundamental skills and abilities to satisfy the needs of their function, and are able to work and cooperate and collaborate in an agreeable way.

\subsection{Core competencies}

A core competence is an organisational capability to perform some aspect of a production function in a manner consistently superior to its competition that in turn leads to above-average organisational performance [7]. According to Clardy [7], core competencies lead to persistent superior performance in several ways as they generate more efficient and effective performance that allow firms to adapt better changing conditions by providing a platform for continuous innovation in products and services.

Sanghi [8] and Vazirani [9] suggest that competencies are divided into two categories: the surface, which are required to be at least effective, and core, which distinguishes superior performance from average performance. The surface competencies are:

- Knowledge: information regarding content, and

- Skills: ability to perform a task. 
The core competencies are:

- Self-concept: values, aptitude, attitude, and self-image;

- Traits: self-confidence, team player, and handles ambiguity, and

- Motives: focus on client success, and preserves organisation / personal integrity.

\subsection{Emotional intelligence}

Songer \& Walker [10] describe Emotional Intelligence (EI) as an "individual's ability to identify emotions in oneself and others and to exhibit appropriate responses to environmental stimuli." Complex projects place additional emphasis on project managers' (PMs) needs for El, because of the unique characteristics such as complexity of personnel, multiplicity of goals, strong uncertainty of activities, and difficulty in coordinating stakeholders, which means there is a 'strong positive correlation between PMs' El and project performance [11].

\subsection{Functions and activities of management work}

Allen identifies two classes of work - mechanical and human. He then subdivides the class of human work into the orders of management work and technical work, and then subdivides the order of management work into functions - planning, organising, leading, and controlling, and suggests a fifth in the form of coordination [12]. The functions of management work are then subdivided into activities - Planning: forecasting; developing objectives; programming; scheduling; budgeting; developing procedures, and developing policies; Organising: developing organization structure; delegating, and developing relationships; Leading: decision making; communicating; motivating; selecting people, and developing people, and Controlling: developing performance standards; measuring performance; evaluating performance, and correcting performance.

\section{Review of the literature}

\subsection{Research method and sample stratum}

The study adopted a quantitative approach and the sample strata included Professional Construction Project Managers (Pr. CPMs), Professional Construction Managers (Pr. CMs), Candidate Construction Project Managers (Can. CPMs), and Candidate Construction Managers (Can. CMs) registered with the South African Council for the Project and Construction Management Professions (SACPCMP).

The questionnaire consisted of twenty-four questions, six of which were demographic, seventeen were closed-ended, of which fifteen were five-point Likert scale type questions, and a further open-ended question. Given that it was a web-based questionnaire survey, the link to the questionnaire and the cover letter, which explained the purpose of the study and instructions regarding how the questionnaire should be completed, were e-mailed to the sample stratum.

Forty-seven responses were received and included in the analysis of the data. The analysis of the data entailed the computation of descriptive statistics in the form of frequencies and a measure of central tendency in the form of a mean score (MS).

\subsection{Research findings}

8.5\% of the respondents were Pr. CPMs, $19.1 \%$ were Pr. CMs, $17.0 \%$ were Can. CPMs, and 34\% were Can. CMs. $70.2 \%$ are employed in the public sector, and $29.8 \%$ are employed in the private sector. $12.8 \%$ were females, and $87.2 \%$ were male. The youngest respondent was 24 years of age and the oldest was 73 years of age. The mean age was 41.7 years. $53.2 \%$ of respondents were 40 years of age or younger, and $46.8 \%$ were older than 40 years of age. Per definition relative to workers, people $>40$ years of age are 'older workers'.

In terms of qualifications, $38.3 \%$ of the respondents have a Bachelors degree, $23.4 \%$ have a National Diploma, $14.9 \%$ have a Honours degree, $8.5 \%$ a Masters degree, $8.5 \%$ a Grade 12 Certificate, and $6.4 \%$ have other qualifications. 
$61.7 \%$ of respondents are mentoring, and $38.3 \%$ are not.

Respondents were required to rate the overall performance of graduates on a scale of 1 (very poor) to 5 (excellent). The resultant MS of 3.47 falls within the range of $>3.40$ to $\leq 4.20$, which indicates that the respondents rate the overall performance of CM graduates as average to good / good.

Table 1 indicates the respondents' rating of graduates' skills prior to employment in terms of percentage responses to a scale of 1 (very poor) to 5 (excellent), and MSs ranging between 1.00 to 5.00 . It is notable that all the MSs $>3.00$, which indicates the respondents rate graduates' skills above average as opposed to below average as in the case of a MS $\leq 3.00$.

Only 1 / 4 (25.0\%) MSs is > $3.40 \leq 4.20$, which indicates the respondents rate graduates average to good / good relative to first ranked academic achievement.

The three (75.0\%) MSs of written communication, oral communication, and interpersonal skills are $>2.60$ to $\leq 3.40$, which indicates the respondents rate the graduates' poor to average / average relative thereto.

Table 1. Respondents' rating of graduates' skills prior to employment.

\begin{tabular}{|c|c|c|c|c|c|c|c|c|}
\hline \multirow{3}{*}{ Skill } & \multicolumn{6}{|c|}{ Response (\%) } & \multirow{3}{*}{ MS } & \multirow{3}{*}{ Rank } \\
\hline & \multirow{2}{*}{$\begin{array}{l}\text { Un- } \\
\text { sure }\end{array}$} & \multicolumn{3}{|c|}{ Very poor...... } & \multicolumn{2}{|c|}{......Excellent } & & \\
\hline & & 1 & 2 & 3 & 4 & 5 & & \\
\hline Academic achievement & 0.0 & 4.3 & 4.3 & 27.7 & 46.8 & 17.0 & 3.68 & 1 \\
\hline Written communication & 0.0 & 2.1 & 19.1 & 38.3 & 25.5 & 14.9 & 3.32 & 2 \\
\hline Oral communication & 0.0 & 2.1 & 19.1 & 40.4 & 27.7 & 10.6 & 3.26 & 3 \\
\hline Interpersonal & 0.0 & 2.1 & 8.5 & 63.8 & 21.3 & 4.3 & 3.17 & 4 \\
\hline
\end{tabular}

Table 2 presents a comparison of respondents' rating of graduates' attributes / skills during and after their probationary period in terms of MSs based upon percentage responses to a scale of 1 (very poor) to 5 (excellent), after-MSs expressed as a multiplier of the before-MSs, and the percentage after-MSs are greater than before-MSs. The attributes / skills are courtesy of Love et al. [2].

It is notable that 14 / 17 (82.4\%) during-MSs as opposed to all (100.0\%) after-MSs are $>3.00$, which indicates the respondents rate the graduates' attributes / skills above average as opposed to below average, as in the case of $3 / 17(17.6 \%)$ during-MSs and no $(0.0 \%)$ MS, which are less than $\leq 3.00$.

It is notable that whereas only $3 / 17(17.6 \%)$ during-MSs are $>3.40 \leq 4.20$, which indicates the respondents rate graduates average to good / good, 16 / 17 (94.1\%) after-MSs are.

Then, whereas 14 / 17 (82.4\%) during-MSs are $>2.60$ to $\leq 3.40$, which indicates the respondents rate the graduates' poor to average / average, only $1 / 17$ (5.9\%) after-MS is.

In terms of the difference between the after and during MSs, it is notable that all after-MSs are higher than during-MSs. The greatest difference is relative to leadership capability (34.2\%), followed by practical building knowledge, adaptable to changing environment, environmental awareness, and problem solving. The least difference is relative to computer literacy (2.4\%), followed by trust and honesty, and numeracy.

Table 2. Comparison of respondents' rating of graduates' attributes / skills during and after their probationary period.

\begin{tabular}{|l|l|l|l|l|l|l|}
\hline \multirow{2}{*}{ Attribute / Skill } & \multicolumn{3}{|l|}{ During } & After & $\begin{array}{l}\text { After/ } \\
\text { Dur }\end{array}$ & $\begin{array}{l}\% \\
\text { After } \\
\text { > Dur }\end{array}$ \\
\cline { 2 - 7 } & MS & Rank & MS & Rank & & \\
\hline Computer literacy & 3.89 & 1 & 3.96 & 1 & 102.4 & 2.4 \\
\hline Numeracy & 3.60 & 2 & 3.85 & 2 & 109.6 & 9.6 \\
\hline Written communication & 3.40 & 4 & 3.77 & 3 & 115.4 & 15.4 \\
\hline Teamwork & 3.26 & 6 & 3.70 & 4 & 119.5 & 19.5 \\
\hline Update professional knowledge & 3.36 & 5 & 3.68 & 5 & 113.6 & 13.6 \\
\hline Trust and honesty & 3.51 & 3 & 3.66 & 6 & 106.0 & 6.0 \\
\hline Oral communication & 3.17 & 7 & 3.60 & 7 & 119.8 & 19.8 \\
\hline
\end{tabular}




\begin{tabular}{|l|l|l|l|l|l|l|}
\hline Interpersonal & 3.17 & 8 & 3.60 & 8 & 119.8 & 19.8 \\
\hline Adaptable to changing environment & 3.13 & 10 & 3.60 & 9 & 122.1 & 22.1 \\
\hline Environmental awareness & 3.06 & 13 & 3.51 & 10 & 121.8 & 21.8 \\
\hline Leadership capability & 2.87 & 16 & 3.51 & 11 & 134.2 & 34.2 \\
\hline Accept responsibility & 3.17 & 9 & 3.47 & 12 & 113.8 & 13.8 \\
\hline Work autonomously & 3.09 & 12 & 3.46 & 13 & 117.7 & 17.7 \\
\hline Exercise professional judgement & 3.09 & 11 & 3.45 & 14 & 117.2 & 17.2 \\
\hline Practical building knowledge & 2.83 & 17 & 3.43 & 15 & 132.8 & 32.8 \\
\hline Time management & 3.06 & 14 & 3.43 & 16 & 118.0 & 18.0 \\
\hline Problem solving & 2.98 & 15 & 3.38 & 17 & 120.2 & 20.2 \\
\hline
\end{tabular}

Table 4 indicates the respondents' rating of graduate's attributes / states prior to employment in terms of percentage responses to a scale of 1 (very poor) to 5 (excellent), and MSs ranging between 1.00 and 5.00. It is notable that $6 / 7$ (85.7\%) MSs > 3.00, which indicates that respondents rate graduate's attributes / states prior to employment as above average as opposed to below average.

Optimism is ranked first based upon a MS of 3.34, indicating that optimism is perceived to impact the performance of graduate's attributes/states prior to employment more than other attributes/states.

The MSs of self-regard, emotional self-awareness, assertiveness, empathy, self-actualisation and impulse control are $>2.60$ to $\leq 3.40$, which indicates that the extent to which respondents perceive the performance of graduate prior to employment in the related attributes/states is poor to average / average.

Table 3. Respondents' rating of graduates' attributes / states prior to employment.

\begin{tabular}{|c|c|c|c|c|c|c|c|c|}
\hline \multirow{3}{*}{ Attribute / State } & \multicolumn{6}{|c|}{ Response (\%) } & \multirow{3}{*}{ MS } & \multirow{3}{*}{ Rank } \\
\hline & \multirow{2}{*}{$\begin{array}{l}\text { Un- } \\
\text { sure }\end{array}$} & \multicolumn{3}{|c|}{ Very poor..... } & \multicolumn{2}{|c|}{.....Excellent } & & \\
\hline & & 1 & 2 & 3 & 4 & 5 & & \\
\hline Optimism & 0.0 & 0.0 & 17.0 & 42.6 & 29.8 & 10.6 & 3.34 & 1 \\
\hline Self-regard & 0.0 & 0.0 & 14.9 & 53.2 & 25.5 & 6.4 & 3.23 & 2 \\
\hline Emotional self-awareness & 0.0 & 0.0 & 19.1 & 48.9 & 25.5 & 6.4 & 3.19 & 3 \\
\hline Assertiveness & 0.0 & 2.1 & 19.1 & 46.8 & 23.4 & 8.5 & 3.17 & 4 \\
\hline Empathy & 0.0 & 2.1 & 17.0 & 53.2 & 23.4 & 4.3 & 3.11 & 5 \\
\hline Self-actualisation & 0.0 & 2.1 & 21.3 & 51.1 & 19.1 & 6.4 & 3.06 & 6 \\
\hline Impulse control & 0.0 & 4.3 & 23.4 & 53.2 & 14.9 & 4.3 & 2.91 & 7 \\
\hline
\end{tabular}

Table 4 presents a comparison of respondents' rating of graduates' attributes / states (EI) during and after their probationary period in terms of MSs based upon percentage responses to a scale of 1 (very poor) to 5 (excellent), after-MSs expressed as a multiplier of the before-MSs, and the percentage after-MSs are greater than before-MSs. The fifteen attributes / states are courtesy of Butler and Chinowsky [13].

It is notable that 14 / 15 (93.3\%) during-MSs as opposed to all (100.0\%) after-MSs are $>3.00$, which indicates the respondents rate the graduates' attributes / states (EQ) above average as opposed to below average, as in the case of $1 / 15(6.7 \%)$ during-MSs and no (0.0\%) afrer-MS, which are less than $\leq 3.00$.

It is notable that whereas only $3 / 15$ (20.0\%) during-MSs are $>3.40 \leq 4.20$, which indicates the respondents rate graduates average to good / good, all (100.0\%) after-MSs are.

Then, whereas 12 / 15 (80.0\%) during-MSs are $>2.60$ to $\leq 3.40$, which indicates the respondents rate the graduates' poor to average / average, no (0.0\%) after-MS is.

In terms of the difference between the after- and during-MSs, it is notable that all after-MSs are higher than during-MSs. The greatest difference is relative to stress tolerance $(29.6 \%)$, followed jointly by interpersonal relationships and problem solving, and self-actualisation. The least difference is relative to happiness (1.2\%), followed by flexibility, and independence. 
Proceedings of the Creative Construction e-Conference (2020) 036

Available online at e-2020.creative-construction-conference.com/proceedings/

Table 4. Comparison of respondents' rating of graduates' attributes / states (EQ) during and after their probationary period.

\begin{tabular}{|c|c|c|c|c|c|c|}
\hline \multirow[b]{2}{*}{ Attribute / State } & \multicolumn{2}{|c|}{ During } & \multicolumn{2}{|l|}{ After } & \multirow[b]{2}{*}{$\begin{array}{l}\text { After / } \\
\text { Dur }\end{array}$} & \multirow{2}{*}{$\begin{array}{l}\% \\
\text { After } \\
>\text { Dur }\end{array}$} \\
\hline & MS & Rank & MS & Rank & & \\
\hline Interpersonal relationships & 3.28 & 10 & 3.68 & 1 & 117.5 & 17.5 \\
\hline Optimism & 3.43 & 3 & 3.66 & 2 & 109.5 & 9.5 \\
\hline Self-regard & 3.32 & 8 & 3.63 & 3 & 113.4 & 13.4 \\
\hline Independence & 3.45 & 2 & 3.62 & 4 & 106.9 & 6.9 \\
\hline Self-actualisation & 3.30 & 9 & 3.62 & 5 & 113.9 & 13.9 \\
\hline Happiness & 3.57 & 1 & 3.60 & 6 & 101.2 & 1.2 \\
\hline Emotional self-awareness & 3.39 & 5 & 3.57 & 7 & 107.5 & 7.5 \\
\hline Problem solving & 3.17 & 14 & 3.55 & 8 & 117.5 & 17.5 \\
\hline Assertiveness & 3.33 & 7 & 3.55 & 9 & 109.4 & 9.4 \\
\hline Flexibility & 3.40 & 4 & 3.51 & 10 & 104.6 & 4.6 \\
\hline Social responsibility & 3.34 & 6 & 3.51 & 11 & 107.3 & 7.3 \\
\hline Reality testing & 3.28 & 11 & 3.51 & 12 & 110.1 & 10.1 \\
\hline Impulse control & 3.19 & 13 & 3.49 & 13 & 113.7 & 13.7 \\
\hline Stress tolerance & 2.89 & 15 & 3.45 & 14 & 129.6 & 29.6 \\
\hline Empathy & 3.22 & 12 & 3.45 & 15 & 110.4 & 10.4 \\
\hline
\end{tabular}

Table 5 indicates the respondents' rating of graduates' core competencies in terms of percentage responses to a scale of 1 (very poor) to 5 (excellent), and MSs ranging between 1.00 and 5.00 . It is notable that all the MSs > 3.00, which indicates that respondents rate graduate's core competencies as above average as opposed to below average.

$5 / 10$ (50.0\%) MSs are $>3.40 \leq 4.20$, which indicates the respondents rate graduates average to good / good relative to personal integrity, self-image, self-confidence, attitude, and team player.

The remaining 5 / 10 (50.0\%) MSs of focus on client success, aptitude, adaptability, values, and handling ambiguity are $>2.60$ to $\leq 3.40$, which indicates the respondents rate the graduates' poor to average / average relative thereto. It should be noted that the MS of focus on client success is 3.40 , the upper limit of the range.

Table 5. Respondents' rating of graduates' core competencies.

\begin{tabular}{|c|c|c|c|c|c|c|c|c|}
\hline \multirow{3}{*}{ Competency } & \multicolumn{6}{|c|}{ Response (\%) } & \multirow{3}{*}{ MS } & \multirow{3}{*}{ Rank } \\
\hline & \multirow{2}{*}{$\begin{array}{l}\text { Un- } \\
\text { sure }\end{array}$} & \multicolumn{2}{|c|}{ Very poor. } & \multirow[b]{2}{*}{3} & \multicolumn{2}{|c|}{......Excellent } & & \\
\hline & & 1 & 2 & & 4 & 5 & & \\
\hline Personal integrity & 0.0 & 0.0 & 14.9 & 36.2 & 27.7 & 21.3 & 3.55 & 1 \\
\hline Self-image & 0.0 & 0.0 & 8.5 & 48.9 & 27.7 & 14.9 & 3.49 & 2 \\
\hline Self-confidence & 0.0 & 0.0 & 17.0 & 38.3 & 25.5 & 19.2 & 3.47 & 3 \\
\hline Attitude & 0.0 & 0.0 & 17.0 & 36.2 & 31.9 & 14.9 & 3.45 & 4 \\
\hline Team player & 0.0 & 0.0 & 19.2 & 34.0 & 29.8 & 17.0 & 3.45 & 5 \\
\hline Focus on client success & 0.0 & 2.1 & 17.0 & 36.2 & 27.7 & 17.0 & 3.40 & 6 \\
\hline Aptitude & 0.0 & 0.0 & 12.8 & 46.8 & 29.8 & 10.6 & 3.38 & 7 \\
\hline Adaptability & 0.0 & 0.0 & 14.9 & 55.3 & 19.2 & 10.6 & 3.26 & 8 \\
\hline Values & 0.0 & 2.1 & 12.8 & 55.3 & 19.2 & 10.6 & 3.23 & 9 \\
\hline Handling ambiguity & 0.0 & 2.1 & 23.4 & 51.1 & 12.8 & 10.6 & 3.06 & 10 \\
\hline
\end{tabular}

Table 6 indicates the respondents' rating of graduate's performance relative to knowledge areas in terms of percentage responses to a scale of 1 (very poor) to 5 (excellent), and MSs ranging between 1.00 and 5.00. It is notable that $6 / 8$ (75.0\%) MSs $>3.00$, which indicates that respondents rate graduate's performance relative to knowledge areas as above average as opposed to below average. However, 5 / 6 (83.3\%) MSs are within 0.13 of 3.00 . 
7 / $8(87.5 \%)$ MSs are $>2.60$ to $\leq 3.40$, which indicates that the extent to which respondents perceive the performance relative to knowledge areas is poor to average / average. Construction technology predominates, followed by construction science, research methodology, construction business environment, construction economics, project management, and management principles and practices. The rank of the latter is notable as it is a 'major' subject in construction management programmes.

The MS of construction law is $>1.80$ to $\leq 2.60$, which indicates that respondents perceive the performance relative thereto is very poor to poor / poor.

Table 6. Respondents' rating of graduates' performance relative to knowledge areas.

\begin{tabular}{|c|c|c|c|c|c|c|c|c|}
\hline \multirow{3}{*}{ Knowledge area } & \multicolumn{6}{|c|}{ Response (\%) } & \multirow{3}{*}{ MS } & \multirow{3}{*}{ Rank } \\
\hline & \multirow{2}{*}{$\begin{array}{l}\text { Un- } \\
\text { sure }\end{array}$} & \multicolumn{3}{|c|}{ Very poor.. } & \multicolumn{2}{|c|}{..Excellent } & & \\
\hline & & 1 & 2 & 3 & 4 & 5 & & \\
\hline Construction technology & 0.0 & 2.1 & 19.2 & 34.0 & 36.2 & 8.5 & 3.30 & 1 \\
\hline Construction science & 0.0 & 2.1 & 23.4 & 42.6 & 23.4 & 8.5 & 3.13 & 2 \\
\hline Research methodology & 0.0 & 4.3 & 23.4 & 38.3 & 27.7 & 6.4 & 3.09 & 3 \\
\hline Construction business environment & 0.0 & 0.0 & 29.8 & 42.6 & 21.3 & 6.4 & 3.04 & 4 \\
\hline Construction economics & 0.0 & 2.1 & 34.0 & 29.8 & 27.7 & 6.4 & 3.02 & 5 \\
\hline Project management & 2.1 & 6.4 & 25.5 & 34.0 & 23.4 & 8.5 & 3.02 & 6 \\
\hline Management principles and practices & 0.0 & 2.1 & 31.9 & 42.6 & 17.0 & 6.4 & 2.94 & 7 \\
\hline Construction law & 0.0 & 4.3 & 40.4 & 29.8 & 17.0 & 8.5 & 2.49 & 8 \\
\hline
\end{tabular}

Table 7 indicates the respondents' rating of graduates' performance relative to the functions of management work in terms of percentage responses to a scale of 1 (very poor) to 5 (excellent), and MSs ranging between 1.00 to 5.00 . It is notable that only $1 / 5$ (20.0\%) MS is marginally $>3.00$, which indicates the respondents rate the performance of graduates relative to organising as above average as opposed to below average as in the case of a MS $\leq 3.00$.

All the MSs are $>2.60$ to $\leq 3.40$, which indicates the respondents rate the graduates' poor to average / average in terms of performance relative to the five functions of management work.

Table 7. Respondents' rating of graduates' performance relative to the functions of management work.

\begin{tabular}{|c|c|c|c|c|c|c|c|c|}
\hline \multirow{3}{*}{ Function } & \multicolumn{6}{|c|}{ Response (\%) } & \multirow{3}{*}{ MS } & \multirow{3}{*}{ Rank } \\
\hline & \multirow{2}{*}{$\begin{array}{l}\text { Un- } \\
\text { sure }\end{array}$} & \multicolumn{5}{|c|}{........Excellent } & & \\
\hline & & 1 & 2 & 3 & 4 & 5 & & \\
\hline Organising & 0.0 & 6.4 & 21.3 & 44.7 & 19.1 & 8.5 & 3.02 & 1 \\
\hline Planning & 0.0 & 4.3 & 29.8 & 42.6 & 10.6 & 12.8 & 2.98 & 2 \\
\hline Coordinating & 0.0 & 8.5 & 25.5 & 36.2 & 21.3 & 8.5 & 2.96 & 3 \\
\hline Controlling & 0.0 & 6.4 & 29.8 & 42.6 & 12.8 & 8.5 & 2.87 & 4 \\
\hline Leading & 2.1 & 6.4 & 46.8 & 25.5 & 12.8 & 6.4 & 2.65 & 5 \\
\hline
\end{tabular}

\section{Conclusions}

Given the respondents' rating of graduates in terms of four skills prior to employment, it can be concluded, that graduates are to a degree prepared for employment. This is underscored by the respondents' rating of graduates in terms of seventeen attributes / skills during their probationary period.

Given the percentage difference between the after- and during-MSs relative to the rating of graduates in terms of seventeen attributes / skills, it can be concluded that the probationary period and related mentoring had an impact. However, the notable difference between the respective MSs relative to leadership capability, practical building knowledge, adaptable to changing environment, environmental awareness, and problem solving, indicates a need for tertiary education interventions.

Given the respondents' rating of graduates in terms of seven of fifteen attributes / states (EI) prior to employment, it can be concluded that graduates are to a degree emotionally intelligent. This is underscored 
by the respondents' rating of graduates in terms of seventeen attributes / skills during their probationary period.

Given the percentage difference between the after- and during-MSs relative to the rating of graduates in terms of fifteen attributes / skills (EI) it can be concluded that, to a degree, the probationary period and related mentoring had an impact. However, the notable difference between the respective MSs relative to stress tolerance, interpersonal relationships, problem solving, and self-actualisation indicates a need for tertiary education interventions. Although stress is a perennial challenge in the construction industry, graduates must be prepared to 'manage' it.

Given the respondents' rating of graduates' core competencies, it can be concluded that graduates are relatively well 'prepared' in terms of core competencies. However, there is a need for attention, particularly with respect to handling ambiguity.

Given the respondents' poor to average / average rating of graduates' performance relative to eight knowledge areas, it can be concluded that there is a need for tertiary education interventions, particularly with respect to construction law.

Given the respondents' poor to average / average rating of graduates' performance relative to the functions of management work, it can be concluded that there is a need for tertiary education interventions. An understanding and appreciation of the functions and their related activities, and the ability to plan, organise, lead, control, and coordinate are critical in industry, and the essence of construction management.

Given the respondents' average to good / good rating of the overall performance of graduates, it can be concluded that the tertiary education process is producing employable graduates.

\section{Recommendations}

Tertiary institutions should ensure that graduates are well versed and developed during their four-year study period. They must be knowledgeable with respect to the 'basics', which includes construction science, technology, management including the management of the business of construction, and construction law. They must be subjected to integrative projects and projects that simulate the construction process, and the practicing of the functions and activities of management work. Emphasis should also be placed on developing core competencies and emotional intelligence through, inter alia, team building activities. Employability and performance must be promoted through nurturing the requisite attributes during tertiary education.

Employers should subject graduates to graduate training programmes to facilitate their integration into the construction industry courtesy of a structured developmental process. Registration as candidates, which requires mentoring by a $\operatorname{Pr} \mathrm{CM}$, will further facilitate such integration.

The interface between industry and tertiary education should be optimised through forums, and the focus should be on promoting and providing vacation work, 'work shadowing', and structured visits to construction businesses and sites, and the delivery of guest lectures by industry practitioners.

Students should consider extracurricular activities such as generic part-time work to compensate for limited vacation or similar work, if the case, thereby developing work-related skills, their core competencies, and El.

\section{References}

[1] Kraak, A., Jewison, R., Pillay, P., Chidi, M., Bhagwan, N., \& Makgolane, M., "Review of the Current Skills Development System and Recommendations towards the best model for delivering skills in the country", Human Resource Development Council of South Africa, Pretoria, 2013.

[2] Love, P.E.D., Haynes, N.S., \& Irani, Z., "Construction managers' expectations and observations of graduates”, Journal of Managerial Psychology, vol 16, nr 8, pp. 579-593, 2001. https://doi.org/10.1108/eum0000000006301.

[3] Kanye, B., \& Crous, F., "Graduate interns experience: A career success orientations approach", SA Journal of Industrial Psychology, vol 33, nr 3, pp. 84-93, 2007. https://doi.org/10.4102/sajip.v33i3.400. 
[4] Pitan, O.S., \& Atiku, S.O., "Structural determinants of students' employability: Influence of career guidance activities", South African Journal of Education, vol 37, nr 4, pp. 1-13, 2017. https://doi.org/10.15700/saje.v37n4a1424.

[5] Jonck, P., "Graduate employability skills in the Public Service", The Independent Journal of Teaching and Learning, vol 12, nr 2, pp. 64-77, 2017.

[6] Ogunsanmi, O.E., "Determining the essential skill requirements for Construction Managers' practice in Nigeria", International Journal of Construction Supply Chain Management, vol 6, nr 2, pp. 48-63, 2016. https://10.14424/ijcscm602016-48-63.

[7] Clardy, A., „Strategy, core competencies and human resource development”, Human Resource Development International, vol 10, nr 3, pp. 339-349, 2007. https://doi.org/10.1080/13678860701516628.

[8] Sanghi, S., The Handbook of Competency Mapping: Understanding, Designing and Implementing Competency Models in Organizations, Second Edition, Sage, New Delhi, 2007. https://doi.org/10.4135/9788132108481.

[9] Vazirani, N., „Competencies and competency model-a brief overview of its development and application”, SIES Journal of Management, vol 7, nr 1, pp. 121-131, 2010.

[10] Songer, A.D. \& Walker, B., General contractor emotional intelligence in the construction industry. In: Khosrowshahi, F (Ed.), 20th Annual ARCOM Conference, 1-3 September 2004, Heriot Watt University. Association of Researchers in Construction Management, vol 1, pp. 487-93, 2004.

[11] Zhang, L. \& Fan, W., „Improving performance of construction projects”, Engineering, Construction and Architectural Management, vol 20, nr 2, pp.195-207, 2013. https://doi.org/10.1108/09699981311303044.

[12] Smallwood, J.J., „The Practice of Construction Management”, Acta Structilia, vol 13, nr 2, pp. 62-89, 2006.

[13] Butler, C.J. \& Chinowsky, P.S., „Emotional Intelligence and Leadership Behaviour in Construction Executives”, Journal of Management in Engineering, vol 22 nr 3, 119-125, 2006. https://doi.org/10.1061/(asce)0742-597x(2006)22:3(119). 